\title{
FLUID FIELD TEMPERATURE OVER A STRETCHING SHEET WITH UNIFORM HEAT FLUX BY MODIFIED HOMOTOPY PERTURBATION TRANSFORM TECHNIQUE
}

\section{B. VENNILA \& J. SASIKUMAR}

Department of Mathematics, School of Basic Sciences, College of Engineering and Technology, SRM Institute of Science and Technology, Kattankulathur, Tamil Nadu, India

\begin{abstract}
In this paper, A modified form of Homotopy perturbation transformed method is proposed to work out a pair of equations during the run of a tacky incompressible liquid caused by means of the stretching sheet. This study shows that a series solution is obtained for velocity and the temperature distribution profile of the fluid by the given methods. The projected procedure finds the result without any off-putting assumptions and avoids the work on errors. This MHPTM for the coupled equation is yet not available in the literature survey. Finally, we reveal how the software enables investigating velocity and heat flux. KEYWORDS: Boundary Layer; Heat Transfer; Stretching Sheet; Prandtl Number; Homotopy Perturbation Method
\end{abstract}

Received: Jun 10, 2020; Accepted: Jun 30, 2020; Published: Aug 04, 2020; Paper Id.: IJMPERDJUN2020615

\section{INTRODUCTION}

Many researchers have paid more concentration on new techniques for solving boundary layer equations. The learning of laminar boundary stream of an incompressible watery has a numeral essential manufacturing submission such as smooth extrusion of synthetic sheets, the cooling of an endless tinny shield in a cooling bath, the boundary layer beside with runny pictures strengthening development, beaker and polymer industries. A joint shape of the Laplace transform scheme through a homotopy perturbation method is used in the direction of cracking the nonlinear equations [1].

The boundary layer run of a nanofluid precedent a stretching sheet has been analyzed numerically [2]. An analytic solution called the homotopy analysis method is applied for the MHD boundary layer stream of a sticky incompressible liquid in excess of an exponentially stretching sheet [3]. The scheme of third array kdv equations also the system of joined Burger's equations within single and double magnitudes are solved by the homotopy perturbation transform method [4]. Elzaki transform homotopy perturbation technique is worned in favor of the temperature ground of a liquid over a stretching sheet by means of uniform heat flux [5]. Incomplete Gamma function is applied for the temperature division in the stream of a thick incompressible fluid caused via the stretching sheet which issues from a cut addicted to the solution [6]. An elementary concept of the homotopy perturbation method is considered [7]. An estimated logical clarification of the magnetohydrodynamic (MHD) margin level current of an Upper-convected Maxwell (UCM) liquefied more than a porous stretching sheet is obtained using homotopy perturbation process [8]. Heat and mass transfer on a stretching sheet with suction or 
blowing is analyzed [9]. The revision is executed for the MHD run owed to a linearly stretching sheet through an convinced magnetic field [10]. A hypothetical scrutiny of the laminar bound-layer flow and heat transport of power-law non-Newtonian fluids over a stretching sheet is investigated by a new procedure based on the homotopy analysis method [11]. Temperature pasture of a flowing in excess of a stretching sheet with uniform heat flux urbanized next to variational homotopy perturbation method [12].The MHD incompressible glutinous fluid pour ended a non-linear stretching sheet among trip circumstance being studied by the process modified homotopy perturbation transform way [13]. A wide separation of analytical solution methods was used to knob boundary layer problems [14-25].

Brilliant and provoked by the constant examine within this region, we employ the modified homotopy perturbation method tied in the company of the Laplace transform for solving the coupled equations in this paper. The proposed technique supplied the solution in a quickly convergent series which may lead to the solution in a closed -form.

The advance of unidentified way is its ability to merge dua influential methods for obtaining accurate solutions for non-

\section{Mathematical Model}

Let us think the case of a smooth sheet supplying from a slim split on $\mathrm{x}=0, \mathrm{y}=0$, and then being extended, while in a polymer processing function. The course made by the stretching of this sheet is guessed to be laminar.

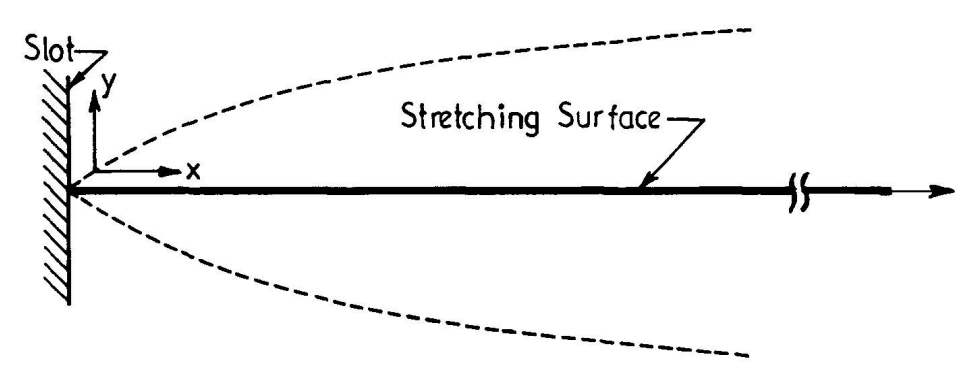

Figure 1: A Draft of Material Problem.

The equations of continuity, momentum, and heat transfer in the boundary layer estimations are

$$
\begin{aligned}
& \frac{\partial u}{\partial x}+\frac{\partial v}{\partial y}=0 \quad \text { (1) } u \frac{\partial u}{\partial x}+v \frac{\partial u}{\partial y}=v \frac{\partial^{2} u}{\partial y^{2}} \\
& u \frac{\partial T}{\partial x}+v \frac{\partial T}{\partial y}=\frac{v}{\sigma} \frac{\partial^{2} T}{\partial y^{2}}
\end{aligned}
$$

where $u$ and $v$ refer the fluid speed mechanism in the $\mathrm{x}$ and $\mathrm{y}$ directions respectively. $\sigma$ stands for Prandtl number, $v$ is the kinematic viscosity.

The boundary settings take the form

$$
\begin{aligned}
& u=\alpha x \text { at } \mathrm{y}=0, \mathrm{v}=0 \text { at } \mathrm{y}=0 \\
& -\lambda \frac{\partial T}{\partial y}=A^{\prime} \text { at } \mathrm{y}=0 \\
& u=0 \text { at } y \rightarrow \infty, T=T_{\infty} \text { at } y \rightarrow \infty
\end{aligned}
$$


where $\alpha$-thermal diffusivity, $\lambda$ - thermal conductivity, $T_{\infty}$ - ambient temperature and

$A^{\prime}$ (uniform surface heat flux).

Let us introduce the dimensionless variable $f$ and $g$ and the similarity variable $\eta$ as

$$
u=\alpha x f^{\prime}(\eta), v=-(\alpha v)^{1 / 2} f(\eta)
$$

$g=\frac{T-T_{\infty}}{T_{w}-T_{\infty}}, \psi=-(\alpha v)^{1 / 2} x f(\eta) \quad$ and $\eta=\left(\frac{\alpha}{v}\right)^{1 / 2} y$

where $\psi$ is the stream function.

By taking the relations $(4 a)-(5 b)$, the boundary layer equation for velocity and temperature fields can be obtained

$$
\begin{aligned}
& f^{\prime \prime \prime}(\eta)=f^{\prime 2}(\eta)-f(\eta) f^{\prime \prime}(\eta) \\
& g^{\prime \prime}(\eta)+\sigma f(\eta) g^{\prime}(\eta)=0
\end{aligned}
$$

The boundary settings are

$$
\begin{aligned}
& f(0)=0, f^{\prime}(0)=1, f^{\prime}(\infty)=0, f^{\prime \prime}(0)=\alpha \\
& g^{\prime}(0)=-1, g(\infty)=0, g(0)=1
\end{aligned}
$$

\section{Solution Procedure for MHPTM}

Applying the MHPTM to the Eq.(6) and(7), we get,

$$
\begin{aligned}
& L(f)=\frac{1}{s^{2}}+\frac{\alpha}{s^{3}}+\frac{1}{s^{3}} L\left(-f f^{\prime \prime}+f^{\prime 2}\right) \\
& L(g)=1-\frac{1}{s^{2}}-\frac{\sigma}{s^{2}} L\left(f g^{\prime}\right)
\end{aligned}
$$

By homotopy perturbation transform method

$$
\begin{aligned}
& \sum_{m=0}^{\infty} p^{m} f_{m}(\eta)=\eta+\frac{\alpha \eta^{2}}{2}+p\left(L^{-1}\left(\frac{1}{s^{3}} L\left(\sum_{m=0}^{\infty} p^{m} H_{1 m}(\eta)-\sum_{m=0}^{\infty} p^{m} H_{2 m}\right)\right)\right) \\
& \sum_{m=0}^{\infty} p^{m} g_{m}(\eta)=(1-\eta)-p \sigma L^{-1}\left[\frac{1}{s^{2}} L\left(\sum_{m=0}^{\infty} p^{m} H_{3 m}(\eta)\right)\right]
\end{aligned}
$$


$G(\eta)=\eta+\frac{\alpha \eta^{2}}{2}=f_{0}(\eta)+f_{1}(\eta)$

as a result of this reflection,we primary set adapted recursive relation in the type,

$$
\begin{aligned}
& p^{0}: f_{0}(\eta)=\eta \\
& p^{1}: f_{1}(\eta)=\frac{\alpha \eta^{2}}{2}+L^{-1}\left(\frac{1}{s^{3}} L\left[H_{10}-H_{20}\right]\right) \\
& =\frac{\alpha \eta^{2}}{2}+\frac{\eta^{3}}{6}+\frac{\alpha \eta^{4}}{24}+\frac{\alpha^{2} \eta^{5}}{120} \\
& p^{2}: f_{2}(\eta)=L^{-1}\left(\frac{1}{s^{3}} L\left[H_{11}-H_{21}\right]\right) \\
& =-\frac{\alpha \eta^{6}}{720}-\frac{\alpha^{2} \eta^{7}}{5040}-\frac{\alpha^{3} \eta^{8}}{40320} \\
& f(\eta)=f_{0}(\eta)+f_{1}(\eta)+f_{2}(\eta)+\ldots \ldots \ldots \\
& f(\eta)=\eta+\frac{\alpha \eta^{2}}{2}+\frac{\eta^{3}}{6}+\frac{\alpha \eta^{4}}{24}+\frac{\alpha^{2} \eta^{5}}{120}+\frac{\alpha \eta^{6}}{720}+\frac{\alpha^{2} \eta^{7}}{5040}+\frac{\alpha^{3} \eta^{8}}{40320}+\ldots \ldots . \\
& p^{(0)}: g_{0}=1-\eta
\end{aligned}
$$

Using modified homotopy perturbation transform method

$$
\begin{aligned}
& G_{1}(\eta)=1-\eta=g_{0}(\eta)+g_{1}(\eta) \\
& p^{0}: g_{0}(\eta)=1
\end{aligned}
$$

$$
p^{(1)}=g_{1}=-\eta+\frac{\alpha \eta^{3}}{6}+\frac{\sigma \alpha \eta^{4}}{24} \quad \text { (23) } p^{(2)}=g_{2}(\eta)=-\frac{\alpha^{2} \eta^{6}}{240}-\frac{\sigma^{2} \alpha \eta^{7}}{840}-\frac{\sigma^{2} \alpha \eta^{7}}{1260}
$$

The series solution is given by

$$
\begin{aligned}
& g(\eta)=\lim _{n \rightarrow \infty} g_{n} \\
& g(\eta)=(1-\eta)+\frac{\sigma \eta^{3}}{6}+\frac{\sigma \alpha \eta^{4}}{24}-\frac{\sigma^{2} \eta^{6}}{240}-\frac{\sigma \alpha^{2} \eta^{7}}{504}-\frac{\sigma^{2} \alpha^{2} \eta^{8}}{4032}+\frac{\sigma \alpha \eta^{6}}{720}+\frac{\sigma \alpha \eta^{7}}{5040}+\frac{\sigma \alpha^{2} \eta^{8}}{40320} \ldots
\end{aligned}
$$

The wall temperature is specified by 


$$
\begin{aligned}
T_{w}-T_{\infty} & =\frac{A^{\prime}}{\lambda}\left(\frac{\gamma}{\alpha}\right)^{1 / 2} g(0) \\
& =\frac{A^{\prime}}{\lambda}\left(\frac{\gamma}{\alpha}\right)^{1 / 2}
\end{aligned}
$$

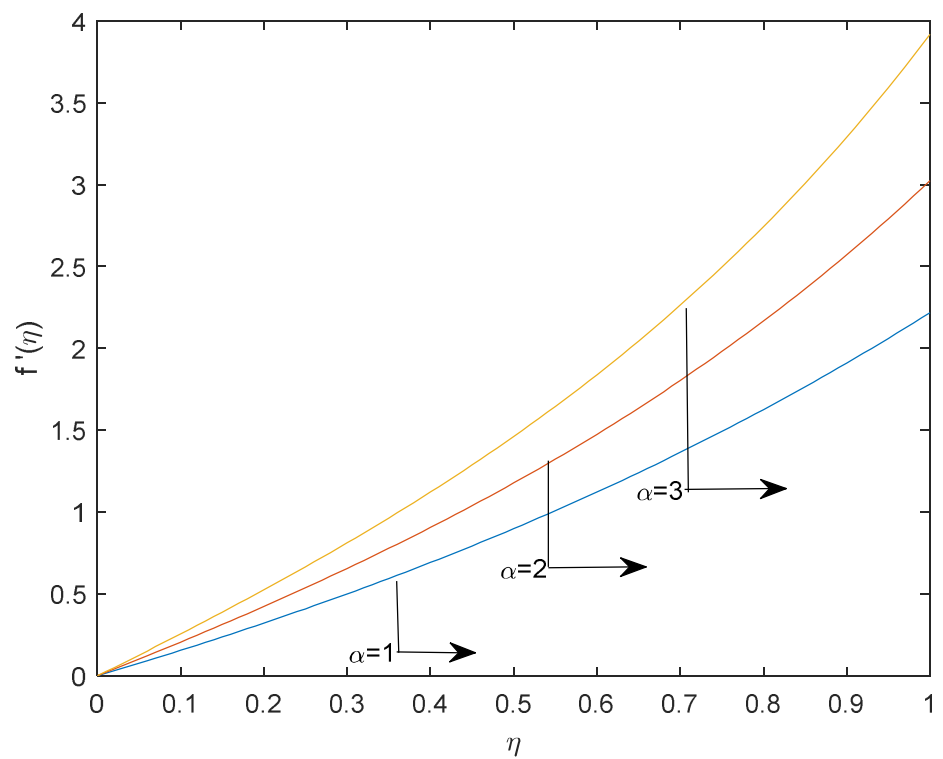

Figure 2: Velocity Outline Designed for Positive Principles of $\alpha$

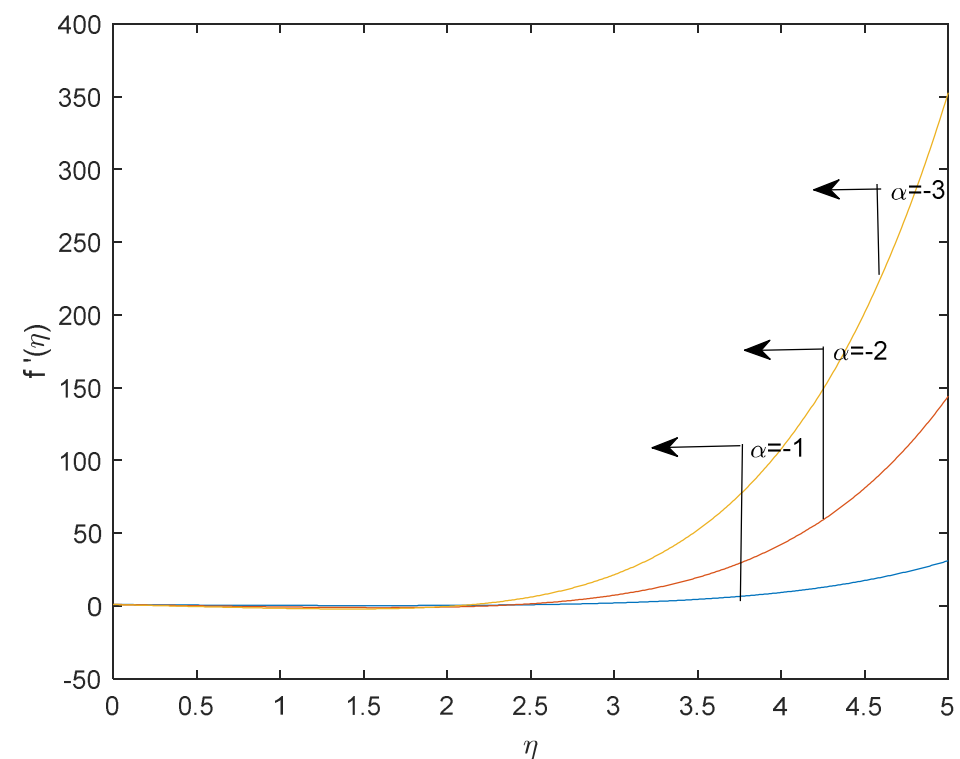

Figure 3: Velocity Outline Designed for Negative Principles of $\alpha$ 


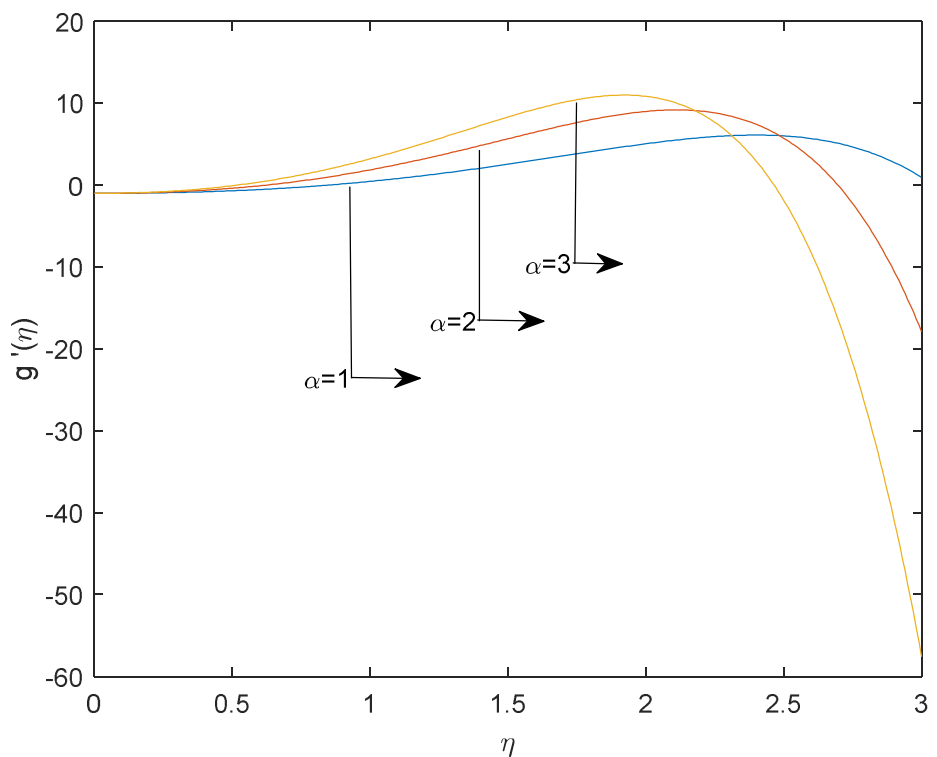

Figure 4: Temperature Distribution with Diverse Ethics of $\alpha$

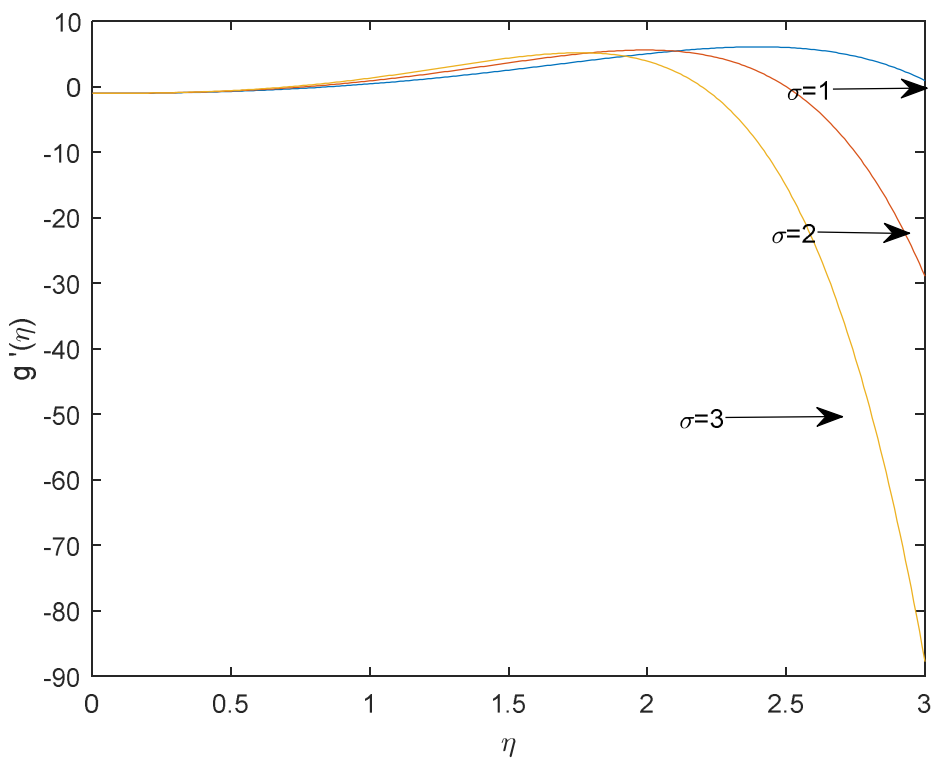

Figure 5: Temperature Distribution with Diverse Ethics of $\sigma$

Table 1: Wall Temperature for Various Values of $\lambda$ and $\alpha$

\begin{tabular}{|c|c|c|c|}
\hline \multicolumn{2}{|c|}{$\lambda=\mathbf{0 . 6}$} & \multicolumn{2}{c|}{$\alpha=\mathbf{0 . 7}$} \\
\hline$\alpha$ & $T_{w}-T_{\infty}$ & $\lambda$ & $T_{w}-T_{\infty}$ \\
\hline 0.2 & 1.1429 & 0.2 & 1.333 \\
\hline 0.4 & 0.5714 & 0.4 & 0.6667 \\
\hline 0.6 & 0.3810 & 0.6 & 0.4444 \\
\hline 0.8 & 0.2857 & 0.8 & 0.3333 \\
\hline
\end{tabular}




\section{RESULTS AND DISCUSSIONS}

Figures.2,3,4 and 5 have been made in to see the impact of thermal diffusivity and Prandtl number in velocity profile moreover temperature distribution. In Fig.2 velocity increases when thermal diffusivity increases. Fig. 3 shows the increase in velocity when we considered the negative value of thermal diffusivity. But initially, the velocity profile is in steady state. It means that fluid flow is not there. After some time we can realize the increase in velocity. In Fig.4 we can see the decreasing trend of the temperature profile with unusual values of $\alpha$ and the Prandtl number be assumed as one.Fig.5 exhibits the nature of the Pranndtl number. To facilitate for the large value of Prandtl number temperature starting from a steady state and to decrease. Fluid temperature decreases owed to the increase in the thermal conductivity parameter.

Table 1 exibits to facilitate the wall temperature reducess when $\alpha$ increases through the fixed value of $\lambda$.Also, wall temperature decreases with the increasing value $\lambda$ with $\alpha=0.7$. It is seen that from table decreasing trend of wall temperature is more for various values of $\alpha$ and compared with different values of $\lambda$.From the table, it can be concluded that wall temperature is significantly high with the effect of thermal diffusivity.

\section{CONCLUSIONS}

In general, the outcomes show that the projected approach is steady as well as convergent. This method provides an easy way to control the convergence region. Edge layer breadth decreases because the fluid velocity rises, higher thermal diffusion means the heat will cover more area and the thermal boundary layer will be thicker. The consequence of expanding the values of the Prandtl number (Pr) is to enhance temperature mostly close to the stretching sheet and the thermal boundary layer width. The Computation of this method (MHPTM) depends on the suitable initial guess.

\section{REFERENCES}

1. Yasir Khan, Qingbiao. Wu.(2011). “Homotopy Perturbation Transform Method for Non-linear Equations using He's Polynomials, “Journal of Computer and Mathematics with Applications, vol.61,No.8, pp: $1963 \quad-$ 1967.doi:https://doi.org/10.1016/j.camwa.2010.08.022.

2. Khan W.A., Pop. I. (2010), “Boundary Layer Flow of a Nanofluid Past a Stretching Sheet, “Journal of Heat and Mass Transfer, vol.53,No.11-12. pp: 2477 - 2483.

3. El-Gamel, M. O. H. A. M. E. D., and M. O. N. A. Sameeh. "A Chebychev collocation method for solving Troesch's problem." International Journal of Mathematics and Computer Applications Research 3.2 (2013): 23-32.

4. Fazle Mabood, Khan W.A., Md. Ismail A.I. (2017), “MHD Flow Over Exponential Radiating Stretching Sheet using Homotopy Analysis Method, "Journal of King Saud University - Engineering Sciences, vol.29, No.1,pp: 68 74.doi:https;//doi.org/10.1016/j.jksues 2014.06-001.

5. Dinakar., Sharma., Prince Singh., Shubha., Chauhan.(2016).Homotopy Perturbation transform method with He's polynomial for solution of coupled "Nonlinear Partial Differential Equations. "Nonlinear Engineering.Vol.61.No.1.pp:1723.doi:10.1514/nleng-2015-0029.

6. Hamoud, AHMED A., et al. "Usage of the modified variational iteration technique for solving Fredholm integro-differential equations." International Journal of Mechanical and Production Engineering Research and Development 9.2 (2019): 895902.

7. Vennila.B.(2017), “Elzaki Transform Homotopy Perturbation Method for Temperature Field of a Fluid Over a Stretching 
Sheet with Uniform Heat Flux. “ARPN Journal of Engineering and Applied Sciences, Vol.12 No.23.pp: 6712 - 6715.

8. Dutta B.K., Roy P., Gupta A.S. (1985), "Temperature Field in Flow Over a Stretching Sheet with Uniform Heat Flux, “International Communications in Heat and Mass Transfer, vol.12.No.1.pp: 89 - 94.doi:https://doi.org/10.1016/0735-1933 (85)90010-7.

9. Ji Huan.He. (2009), “An Elementary Introduction to the Homotopy Perturbation Method, "Computer and Mathematics with Applications, vol.57, No.3, pp: 410 - 412.https;//doi.org/10.1016/j.camea.2008.06.003.

10. Sweilam, N. H., M. M. Khader, and M. Adel. "An efficient class of FDM based on Hermite formula for solving fractional reaction-subdiffusion equations." Int. J. Math. Comput. Appl. Res 2 (2012): 61-75.

11. Behrouz Raftari, Ahmet Yildirim, (2010), “The Application of Homotopy Perturbation Method for MHD Flows of UCM Fluids above Porous Stretching Sheet, "Computer and Mathematics with Applications, vol.59.No.10. pp: 3328 3337.https://doi.org/10.1016/j.camwa.2010.03.018.

12. Gupta P.S., Gupta A.S.(1977), "Heat and Mass Transfer on a Stretching Sheet with Suction or Blowing, "The Canadian Journal of Chemical Engineering, vol.55.No.6. pp: 744 - 746.https://doi.org/10.1002/cjce.5450550619.

13. Tarek M.A., El-Mistikawy, (2018). "Heat Transfer in MHD Flow due to a Linearly Stretching Sheet with Induced Magnetic Field, "Advances in Mathematical Physics, vol.2018. pp:8.

14. https://doi.org/10.1155/2018/5686089.

15. JAIN, NAINY, and ARCHANA LALA. "COLOUR IMAGE SEGMENTATION: FUZZY CONNECTEDNESS." Research and Development (IJECIERD) 3.4 (2013): 133-146.

16. Chung Liu, Ahmed Megahed.M. (2012). "Homotopy Perturbation Method for Thin Film Flow and Heat Transfer Over an Unsteady Stretching Sheet with Internal Heating and variable Heat Flux, “Journal of Applied Mathematics, vol.2012. pp: 12. http://dx.doi.org/10.1155/2012/418527.

17. Hang X.U., Shi-Jun Liao.(2009). "Laminar Flow and Heat Transfer in the Boundary Layer of Non-Newtonian Fluids Over a Stretching Flat Sheet, "Computer and Mathematics with Applications, vol.57. pp: $1425 \quad-\quad 1431$. https://doi.org/10.1016/j.camwa.2009.01.029

18. Vennila.B.(2018). "Temperature Field of a Fluid over a Stretching Sheet with Uniform Heat Flux by Variational Homotopy Perturbation Method, "International Journal of Pure and Applied Mathematics, vol.119.pp: 111 - 119. doi: 10.12732/ijpam.v119i1.9.

19. Yasir khan.,Muhammad Usman.(2014). "Modified homotopy perturbation transform method:A paradigm for Non linear Boundary value problems, “Int.J.Nonlinear sci.Number.simul, vol.15.no.1.pp:19-25.doi:10.1515/ijnsn.2011.0065.

20. James collatz.G.,Timothy ball.J.,Cyril Grivel.,Joseph A berry.(1991). "Physiological and environmental regulation of stomatal conductance, "photosynthesis and transpiration: a model that includes a laminar boundary layer.Agricultural and Forest Meteorology,Vol.54,No.2-4 pp;107-136.

21. https://doi.org/10.1016/0168-1923(91)90002-8

22. Lan.Xu.(20070. "He's Homotopy perturbation method for a boundary layer equation in unbounded domain, "Computers and Mathematics with Applications with applications, Vol.54.no.7-8.pp:1067- 1070.https://doi.org/10.1016/j.camwa.2006.12.052.

23. Jhankal.A.K(2014). "Homotopy perturbation method for MHD boundary layer flow with low pressure Gradient over a flat plate, “Journal of Applied Fluid Mechanics, Vol.7.No.1.pp:177-185. 
24. Fazl.E.Mabood.,Waquar.A>Khan.,Ahmad Izani Ismail.(2013). "Solution of nonlinear boundary layer

25. equation for flat plate via optional homotopy asymptotic method, "Heat Transfer Asian Research,Vol.43, No.3.pp:197203.https://doi.org?10.1002/htj.21070.

26. Hamza Berrehal.,Abdelaziz Maougal.(2016). "High order He’s Homotopy Perturbation Method solution for boundary layer flow, “International Journal of Modern Mathematical Sciences, Vol.14. no.4.pp:365-375.

27. Alireza Majidian,Khaki.M.,Khazayinejad.M.(2012). "Analytical solution of laminar Boundary layer Equations over a flat plate by homotopy Perturbation Method, “International Journal of Applied Mathematics Research,vol.1.No.4.pp:581-592.

28. Yinlong Zaho,Zhiliang lin.,Shijun Lia.(2013). “A Modified Homotopy Analysis method for solving Boundary Layer Equations, “Applied Mathematics,Vol.4.No.1.pp:5.doi:10.4236/am.2013.41003.

29. Aghakhani.M.,Suhatril.M.,Mohammadhassani.M.,Daie.M.,Toghroli.A(2015). “A simple modification of Homotopy Perturbation method for the solution of Blasius Equation in semi-infinite domains, "Mathematical Problems in Engg,Vol.2015.pp:7. http://dx.doi.org/10.1155/2015/671527.

30. Domairry.G., Ziabakhsh.Z.(2012). "Solution of boundary layer flow and heat transfer of an electrically conducting Micropolar fluid in a non Darcian porous medium, "Meccanica, Vol.47. No.1.pp:195-202.

31. Mehran Khaki Jamei,Mehdi Khazayinejad,davood Domairry Ganji.(2014). "New Results for boundary layerflow and convection Heat Transfer over a flat plate by using the Homotopy Perturbation Method, "Malailak Journal of Science and technology,Vol.11.No.4.pp:1-16. http://dx.doi.org/10.14456/WJST.2014.47.

32. Rostamiyan.M., Khazayainejad M.,Ganji.DD.,Hamed Mashhadzadeh.A.(2014). “Application of the boundary layer flow and heat transfer over a flat plate using coolaction method, "Proceedings of the Institution of Mechanical Engg. Vol.230. no.5. pp: 385-393.

33. https://doi.org/10.1177/0954408914556560.

\section{BIBLOGRAPHY}

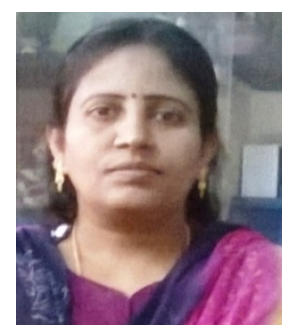

Dr. B.Vennila is from Perungalathur near Chennai. She is working as an Associate professor in SRM Institute of science and technology, Chennai. She acknowledged her Ph.D.degree in the area of Fluid dynamics from SRM University Chennai in 2010.She completed her MPhil mathematics from Alagappa University, Karaikudi in the year 1996. B.sc and M.sc Mathematics from Seethalakshmi achi college for women, Karaikudi in the year 1990-1995. Her area of research interest is rotating fluid and stretching sheet problems. She is a member of ISTE, IMS, IAENG and ISCO. 


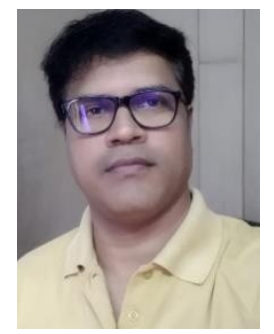

Mr.J.Sasikumar is from Chennai, India. He is working as Assistant Professor, Department of Mathematics in SRM Institute of Science and Technology, Kattankulathur-603203.He submitted his Ph.D. thesis to SRM Institute of Science and Technology in September 2019, doing research in the area fluid dynamics. He completed M.Phil. (Mathematics) with specialization in Number Theory and M.Sc. (Mathematics) during the year 1987-1991 from R.K.M. Vivekananda college, Chennai. He has total of 28 years of teaching experience in science and engineering colleges. He is the member of ISTE and IMS. 